\title{
Perbandingan Rata-Rata Densitas Pada Hasil Foto Thorax Proyeksi Antero Posterior (AP) Supine dan Duduk Tegak
}

\author{
${ }^{1}$ Ali Amroji, ${ }^{2}$ Raditya Faradina Pratiwi, ${ }^{3}$ Agnes Andriana \\ $1,2,21,2,3$ ATRO Nusantara
}

Corresponding author: Raditya Faradina Pratiwi

Email: radityafaradina@gmail.com

\begin{abstract}
Background: This research aims for knowing the differences of the average density thorax photo in position AP Supine and AP of Sitting Position. In the AP projections Supine and AP sit upright will get an average density that is not significant and affect the quality of the image to be not optimal. So that further efforts are needed so that the use of the AP projection sits upright to obtain an optimal picture quality such as the use of the AP projections Supine (Firdausy, 2011)

Methods: This Scientific research is quantitative with evaluating the average differences on the four points. First patient's sample did four photos, meanwhile the second patients only done with two photos. The density Measurement using densitometry, this Measurement is for knowing the average point from evert photo and exposure factor changes using certain formula and later on will be compared the first photo until the last photo. Creating percentage for the increased mAs value on the Thorax Projection of the sitting position.

Results: This research shows that Thorax Projection AP of Sitting position can be combined with the average density with the photos of the Thorax Projection AP Supine

Conclusions: This research shows, a significant difference in average density was obtained between the images of the AP Supine Projection and the AP Sit Upright. The average density value in the AP Supine Radiograph is greater than the AP Seated Upright and to produce an average density that is almost the same for the AP supine projection with FFD $100 \mathrm{~cm}$ and the AP projection sitting upright with FFD 150 it is necessary to add an mAs value of $50 \%$ to the AP projection sits upright from the mAs value used in the supine AP projection
\end{abstract}

Keyword : Radiology; Thorax; Density

\section{Pendahuluan}

Penemuan sinar tersebut sangat bermanfaat bagi dunia kedokteran, karena sinar X dapat digunakan untuk memeriksa bagian tubuh manusia.Perkembangan ilmu dalam bidang radiologi sekarang ini banyak mengalami kemajuan yang sangat pesat. Hal ini dapat dilihat dari banyaknya jenis pemeriksaan radiografi yang dapat dilakukan dengan menggunakan sinar-x.

Untuk dapat menghasilkan gambaran radiografi yang baik, maka diperlukan pengetahuan mengenai teknik radiografi. Gambaran radiografi harus memiliki kualitas gambaran yang baik dilihat dari faktor densitas, kontras, detail dan ketajaman sehingga dapat memberikan informasi yang optimal dari suatu gambaran. Salah satu faktor penting dalam menghasilkan kualitas gambaran seperti yang dimaksud diatas adalah dengan menentukan pengaturan faktor eksposi secara tepat.

Hal lain yang harus diperhatikan dalam menggunakan faktor eksposi salah satunya adalah penggunaan arah sinar Vertikal dan Horizontal karena arah sinar berhubungan dengan menentukan posisi pasien. Pada umumnya pemeriksaan thorax digunakan proyeksi rutin yaitu PA Erect dan Lateral $\mathrm{R}$ atau L. Dimana saat proyeksi thorax PA erect akan menghasilkan gambaran jantung dengan bentuk normal sehingga menghasilkan gambaran yang baik sesuai dengan diagnosa. 
Namun, dari hasil penelitian penulis dilapangan, untuk pasien yang non kooperatif akan dibuat foto thorax dengan proyeksi AP Supine dengan arah sinar Vertikal. Tetapi untuk klinis tertentu seperti efusi pleura dibutuhkan proyeksi AP duduk tegak dengan arah sinar Horizontal, dimana posisi tersebut akan lebih terlihat jelas volume cairan di paru-paru dan gambaran jantung akan lebih terlihat pada batas normal.

Pada proyeksi AP Supine dan AP duduk tegak akan memperoleh rata-rata densitas yang tidak signifikan dan mempengaruhi kualitas gambaran menjadi tidak optimal. Sehingga perlu upaya lebih lanjut agar penggunaan pada proyeksi AP duduk tegak memperoleh kualitas gambaran menjadi optimal seperti penggunaan pada proyeksi AP Supine (Ahmad Fahrurrozi Firdausy, 2011).

\section{Metode}

Penelitian ini bersifat kuantitatif yaitu dengan melakukan penelitian langsung dari lapangan dengan mengambil beberapa sample data berupa foto Thorax dengan proyeksi berbeda, kemudian mengukur densitas dengan menggunakan alat densitometer dan menghitung perbedaan faktor eksposi pada densitas yang lebih rendah. Penelitian ini dilakukan pada bulan Juni sampai dengan Juli 2016.

Setelah mendapatkan hasil gambaran, tahap selanjutnya adalah dengan menghitung densitas pada hasil foto nomor satu dan nomor empat dengan titik Lung Field, Lung Periphery, Mediastinum, dan Cardiac Shadow. Kemudian hitung rata-rata densitasnya dengan menggunakan rumus statistik kuantitatif (weighted mean score). Jika diperoleh nilai rata-rata densitas dengan perbedaan yang signifikan maka akan dilakukan perubahan faktor eksposi dengan menggunakan penghitungan konversi pada selisih densitas.

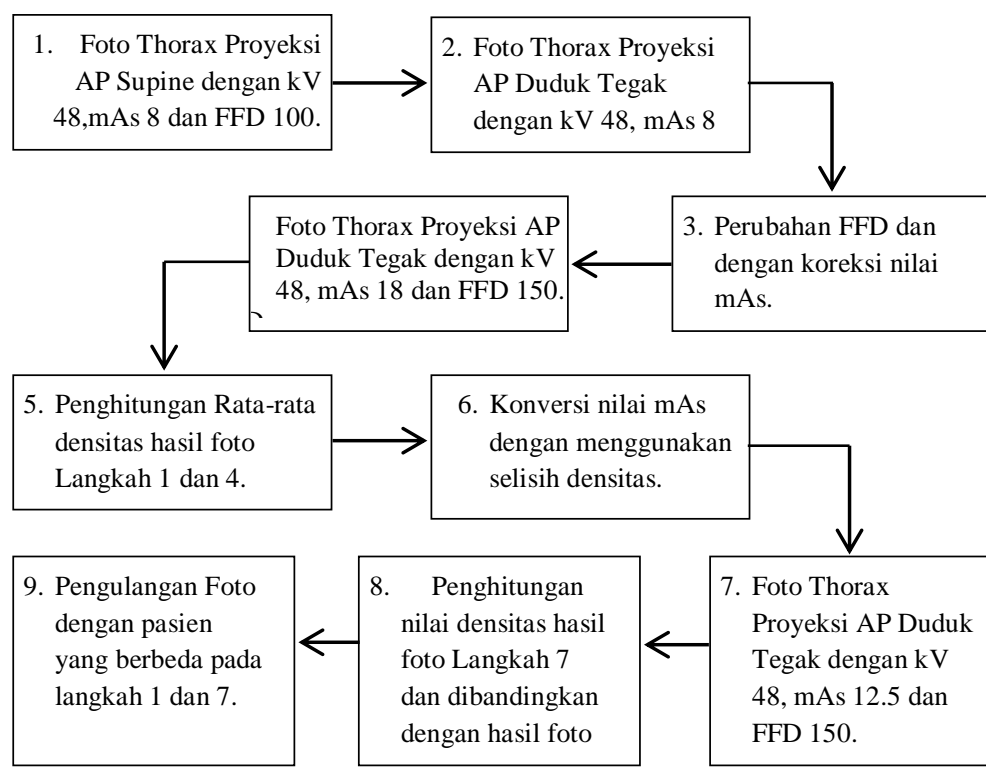

Gambar 1. Bagan Alur Penelitian

\section{Hasil dan Pembahasan}

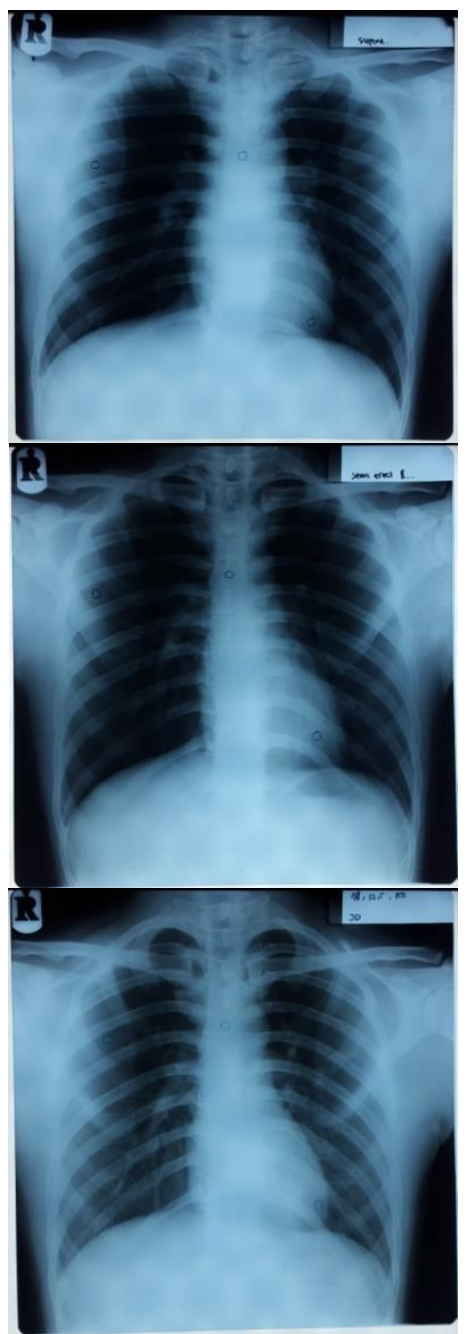

(a)

(b)

(c)

Gambar 2 (a), Proyeksi AP Supine. (b) dan (c) Proyeksi AP Duduk Tegak 
Gambar 2 di atas merupakan hasil gambaran foto thorax pada foto pertama menggunakan faktor eksposi $\mathrm{kV} 48, \mathrm{mAs} 8$ dan FFD 100. Lalu foto kedua menggunakan faktor eksposi kV 48 mAs 18 dan FFD 150. Sedangkan foto ketiga menggunakan faktor eksposi kV 48, mAS 12.5 dan FFD 150
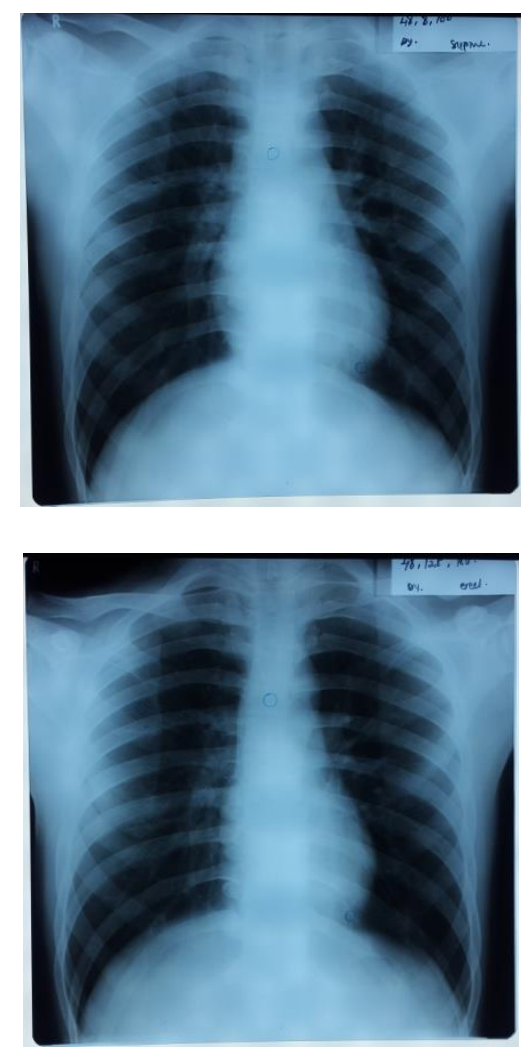

(b)

Gambar 3 (a), Proyeksi Supine. (b), Proyeksi AP Duduk Tegak

Pada Foto pertama menggunakan faktor eksposi $\mathrm{kV} 48$, mAs 8 dan FFD 150 dan foto kedua menggunakan faktor eksposi $\mathrm{kV} 48$, mAs 12.5 dan FFD 150.

\section{Langkah ke 1}

Pasien di foto Thorax dengan Proyeksi AP. Posisi pasien Supine dengan kedua tangan pasien berada disamping tubuh. Mid Sagital tubuh dipertengahan kaset dan batas atas kaset tiga jari diatas bahu. Center point setinggi Vertebrae Thoracal 7 atau sejajar axilla. Central ray tegak lurus kaset. Faktor Eksposi yang digunakan yaitu $\mathrm{kV}$ 48, mAs 8 dan FFD 100

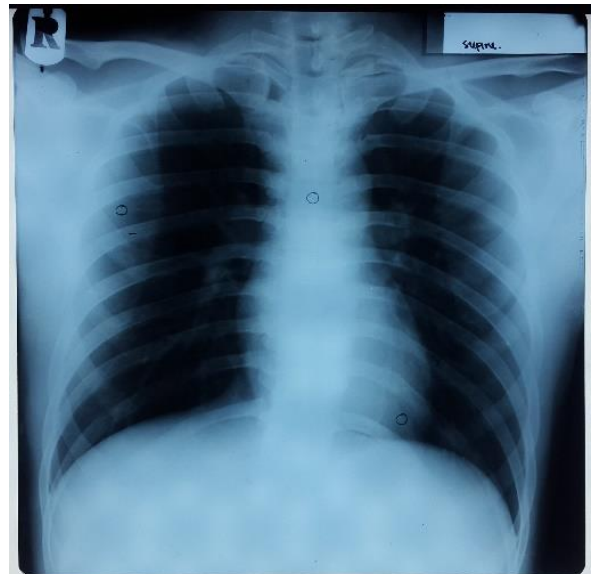

\section{Gambar 4 Foto Thorax Proyeksi AP Supine}

\section{Kriteria Gambaran:}

1. Seluruh lapangan paru tampak atau tercover dan terlihat cukup untuk densitasnya.

2. Thoracal 1-4 tampak terlihat samar.

3. Batas bawah kedua Sinus Costoprenicus tampak tidak terpotong.

4. Tampak gambaran valkularisasi paru.

5. Lapangan Pulmo terutup dari gambaran os. Scapula.

6. Inspirasi penuh ditunjukkan dengan terlihatnya Costae 9-10 Posterior.

7. Tampak gambaran jantung dengan panjang $12 \mathrm{Cm}$.

\section{Langkah ke 2}

Pasien di foto sama seperti langkah pertama, yang berbeda hanya posisi pasien yaitu duduk tegak.

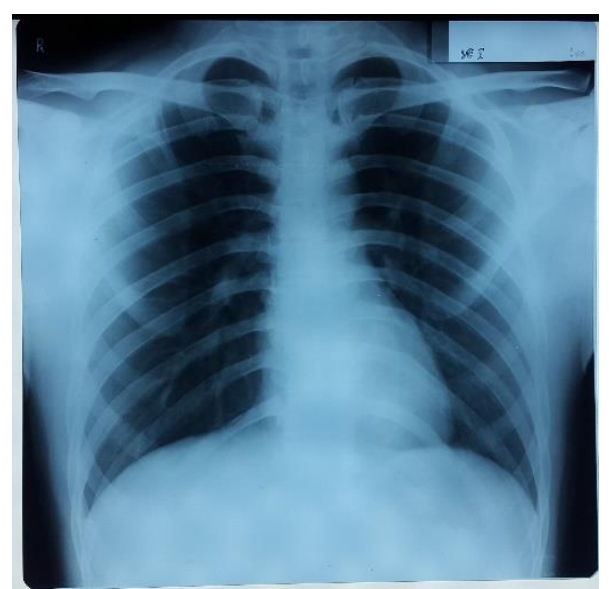

Gambar 5 Foto Thorax Proyeksi AP Duduk Tegak 
Kriteria gambaran:

1. Seluruh lapangan paru tampak atau tercover dan terlihat kurang untuk densitasnya.

2. Thoracal 1- 4 tampak terlihat samar.

3. Batas bawah kedua Sinus Costoprenicus tampak tidak terpotong.

4. Tampak gambaran valkularisasi paru.

5. Lapangan Pulmo terutup dari gambaran os. Scapula.

6. Inspirasi penuh ditunjukkan dengan terlihatnya Costae 9-10 Posterior.

7. Tampak gambaran jantung dengan panjang $11,5 \mathrm{Cm}$.

\section{Langkah ke 3}

Perubahan FFD dengan menggunakan penghitungan Koreksi Jarak Fokus Film (FFD) yaitu:

mAs baru $=\frac{\text { Jarak baru }^{2}}{\text { Jarak lama }^{2}} \times$ mAs lama

$\frac{150^{2}}{100^{2}} \times 8=\frac{22.500}{10.000} \times 8=\mathbf{1 8}$

Jadi mAs pada penggunaan FFD $150 \mathrm{~cm}$ adalah 18.

\section{Langkah ke 4}

Pasien di foto sama seperti langkah kedua, yang berbeda hanya faktor eksposinya yaitu $\mathrm{kV}$ 48, mAs 18 dan FFD 150.

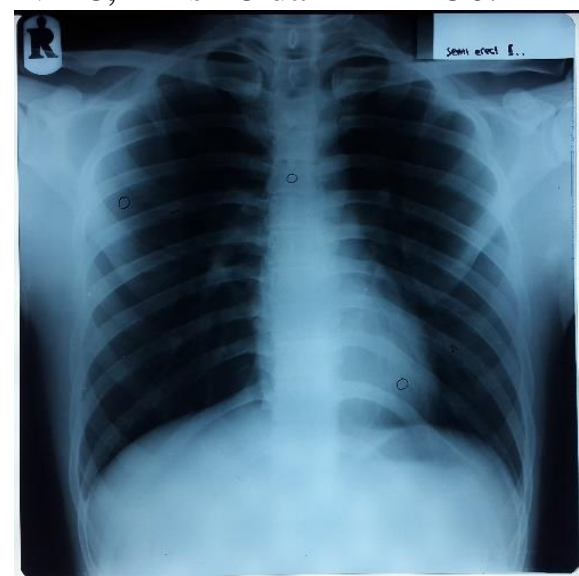

Gambar 6 Foto Thorax Proyeksi AP Duduk Tegak dengan mAs 18
Kriteria gambaran:

1. Seluruh lapangan paru tampak atau tercover dan lebih terlihat lebih gelap untuk densitasnya.

2. Thoracal 1-5 tampak terlihat samar.

3. Batas bawah kedua Sinus Costoprenicus tampak tidak terpotong.

4. Tampak gambaran valkularisasi paru.

5. Lapangan Pulmo terutup dari gambaran os. Scapula.

6. Inspirasi penuh ditunjukkan dengan terlihatnya Costae 9-10 Posterior.

7. Tampak gambaran jantung dengan Panjang $11 \mathrm{Cm}$.

\section{Langkah ke 5}

Penghitungan nilai densitas dengan menggunakan rumus weighted mean score.

Tabel 1 Rata-rata densitas langkah pertama dan keempat

\begin{tabular}{|c|c|c|c|}
\hline \multicolumn{2}{|c|}{$\begin{array}{c}\text { Foto pada langkah } \\
\text { pertama }\end{array}$} & \multicolumn{2}{|c|}{ Foto pada langkah keempat } \\
\hline Lung Field & 1.96 & Lung Field & 2.02 \\
\hline Lung Periphery & 0.74 & Lung Periphery & 1.06 \\
\hline Mediastinum & 0.38 & Mediastinum & 0.81 \\
\hline $\begin{array}{l}\text { Cardiac } \\
\text { Shadow }\end{array}$ & 0.89 & $\begin{array}{l}\text { Cardiac } \\
\text { Shadow }\end{array}$ & 0.87 \\
\hline $\begin{array}{r}\text { Rata-rata } \\
\text { densitas }\end{array}$ & 0.99 & $\begin{array}{r}\text { Rata-rata } \\
\text { densitas }\end{array}$ & 1.19 \\
\hline \multicolumn{4}{|c|}{ Selisih dari rata-rata densitasnya adalah 0.20} \\
\hline
\end{tabular}

Menurut penelitian, kualitas x-ray Thorax terdapat empat daerah tertentu yang harus hati-hati untuk didiagnosis. Empat bidang yang penting dalam Fields paru-paru adalah Lung Field, Lung Periphery, Mediastinum dan Cardiac Shadow (Handbook On Quality Assurance of Chest Radiography, 2008). Maka dalam pengambilan nilai densitas dari keempat titik di atas dapat dilihat perbandingan nilai rata-rata pada titik Lung field, Lung periphery dan Mediastium pada foto keempat lebih besar nilai rata-ratanya daripada foto pertama, Sedangkan nilai ratarata pada titik Cardiac Shadow lebih besar nilainya dari foto pertama dibanding foto keempat. Dimana diperoleh selisih nilai ratarata densitas dari kedua foto tersebut yaitu 0.20.

\section{Langkah ke 6}

Konversi nilai mAs dengan menggunakan 
selisih densitas.

Dalam teori Konversi nilai mAs dikatakan "Kenaikan nilai mAs dua kali akan menambah opasitas sebanyak dua kali dan menaikan densitas sebesar 0.3 OD”. Sehingga jika sebuah radiograf terjadi kelebihan densitas sebanyak 0.3 OD, maka untuk mengkoreksinya harus dilakukan pengurangan nilai $\mathrm{mAs}$ separuh dari nilai mAs yang digunakan. Pada hasil percobaan langkah pertama dan keempat diperoleh selisih 0.2 OD pada pemakaian mAs awal 18 mAs sehingga untuk mengkoreksinya dilakukan pengurangan nilai mAs menjadi 12, tetapi karena dipengaturan faktor eksposi pesawat tidak bisa 12 maka nilai mAs menjadi 12.5.

\section{Langkah ke 7}

Pasien difoto sama seperti langkah keempat, yang berbeda hanya faktor ekposinya yang telah diselisihkan densitasnya menjadi kV 48, mAs 12.5 dan FFD 150.

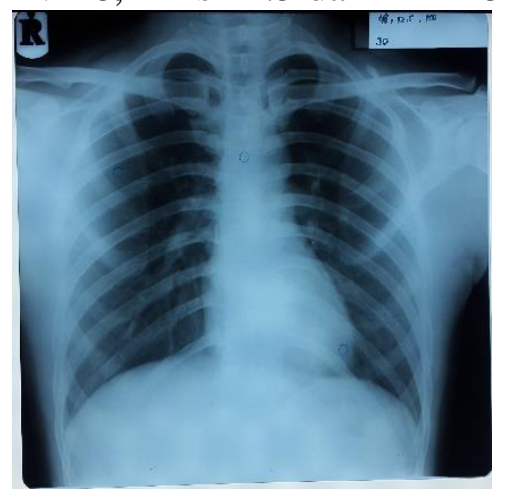

Gambar 7 Foto Thorax Proyeksi AP Duduk Tegak dengan mAs 12.5

Kriteria gambaran:

1. Seluruh lapangan paru tampak atau tercover dan terlihat cukup untuk densitasnya.

2. Thoracal 1-4 tampak terlihat jelas.

3. Batas bawah kedua Sinus Costoprenicus tampak tidak terpotong.

4. Tampak gambaran valkularisasi paru.

5. Lapangan Pulmo terutup dari gambaran os. Scapula.

6. Inspirasi penuh ditunjukkan dengan terlihatnya Costae 9-10 Posterior.

7. Tampak gambaran jantung dengan panjang $11 \mathrm{Cm}$.

\section{Langkah ke 8}

Penghitungan nilai densitas hasil foto Langkah 7 dan dibandingkan dengan hasil foto Langkah 1.

Tabel 2 Rata-rata densitas langkah ketujuh dan pertama

\begin{tabular}{|c|c|c|c|}
\hline \multicolumn{2}{|c|}{$\begin{array}{c}\text { Foto pada langkah } \\
\text { ketujuh }\end{array}$} & \multicolumn{2}{|c|}{ Foto pada langkah pertama } \\
\hline Lung Field & 1.62 & Lung Field & 1.96 \\
\hline Lung Periphery & 0.95 & Lung Periphery & 0.74 \\
\hline Mediastinum & 0.50 & Mediastinum & 0.38 \\
\hline $\begin{array}{l}\text { Cardiac } \\
\text { Shadow }\end{array}$ & 0.69 & $\begin{array}{l}\text { Cardiac } \\
\text { Shadow }\end{array}$ & 0.89 \\
\hline $\begin{array}{r}\text { Rata-rata } \\
\text { densitas }\end{array}$ & 0.94 & $\begin{array}{r}\text { Rata-rata } \\
\text { densitas }\end{array}$ & 0.99 \\
\hline
\end{tabular}

Pada tabel di atas dapat dilihat pada titik Lung Field dan Cardiac Shadow lebih besar nilai rata-rata densitas pada foto pertama dibanding foto ketujuh, sedangkan pada titik Lung Periphery dan Mediastinum lebih besar nilai rata-rata densitas pada foto ketujuh dibanding foto pertama. Dimana diperoleh selisih nilai rata-rata densitas dari kedua foto tersebut yaitu $\mathbf{0 . 0 4}$.

\section{Langkah ke 9}

Pengulangan Foto dengan pasien yang berbeda pada langkah pertama dan ketujuh.

Pertama pasien difoto dengan faktor eksposi yang sama pada langkah pertama dan langkah ketujuh.

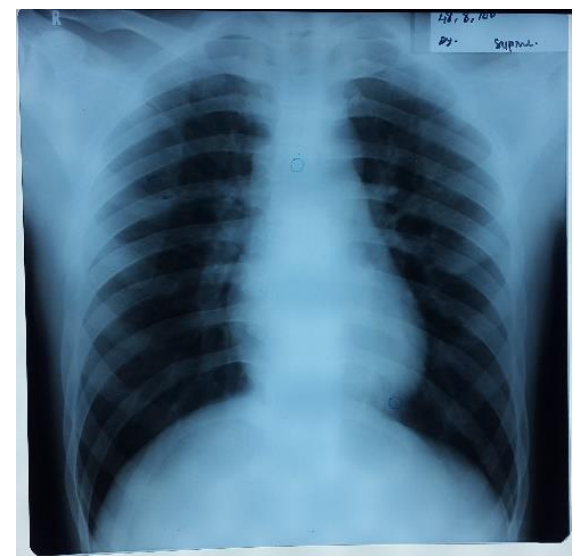




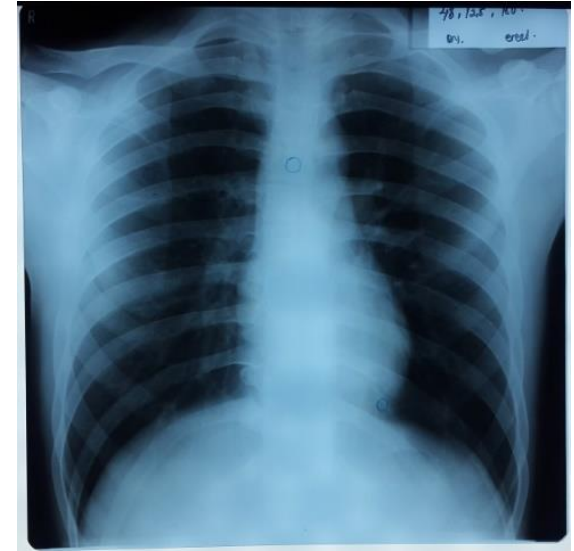

Gambar 8 (a), Hasil Foto Thorax Supine. (b), Hasil Foto Duduk Tegak dengan mAs 12.5.

Penghitungan rata-rata densitas hasil foto $\mathrm{A}$ dengan pasien yang berbeda.

Tabel 3 Rata-rata densitas Langkah petama dan ketujuh pada pasien berbeda

\begin{tabular}{|l|l|l|c|}
\hline \multicolumn{2}{|c|}{$\begin{array}{c}\text { Foto pada langkah } \\
\text { pertama }\end{array}$} & \multicolumn{2}{c|}{ Foto pada langkah ketujuh } \\
\hline Lung Field & 1.67 & Lung Field & 1.64 \\
\hline Lung Periphery & 1.20 & Lung Periphery & 1.19 \\
\hline Mediastinum & 0.34 & Mediastinum & 0.43 \\
\hline $\begin{array}{c}\text { Cardiac } \\
\text { Shadow }\end{array}$ & 0.88 & $\begin{array}{l}\text { Cardiac } \\
\text { Shadow }\end{array}$ & 0.78 \\
\hline $\begin{array}{c}\text { Rata-rata } \\
\text { densitas }\end{array}$ & $\mathbf{1 . 0 2}$ & $\begin{array}{c}\text { Rata-rata } \\
\text { densitas }\end{array}$ & $\mathbf{1 . 0 1}$ \\
\hline & & \\
\hline
\end{tabular}

Selisih dari rata-rata densitasnya adalah 0.01

Tabel di atas merupakan nilai rata-rata dari hasil foto Thorax dengan pasien yang berbeda. Dapat dilihat dari titik Lung Field, Lung Periphery dan Cardiac Shadow nilai rata-rata densitasnya lebih besar pada foto pertama dibanding foto ketujuh, sedangkan untuk titik Mediastinum nilai rata-rata densitasnya lebih besar foto ketujuh dibanding foto pertama. Dimana diperoleh selisih nilai rata-rata densitas dari kedua foto tersebut yaitu $\mathbf{0 . 0 1}$

Pada umumnya pemeriksaan thorax digunakan proyeksi rutin yaitu PA Erect dan Lateral $\mathrm{R}$ atau L. Dimana saat proyeksi thorax PA erect akan menghasilkan gambaran jantung dengan bentuk normal sehingga menghasilkan gambaran yang baik sesuai dengan diagnosa. Namun untuk pasien yang non kooperatif akan dibuat foto thorax dengan proyeksi AP Supine dengan arah sinar Vertikal. Tetapi untuk klinis tertentu seperti efusi pleura dibutuhkan proyeksi AP duduk tegak dengan arah sinar Horizontal, dimana posisi tersebut akan lebih terlihat jelas volume cairan di paruparu dan gambaran jantung akan lebih terlihat pada batas normal. Pada proyeksi AP Supine dan AP duduk tegak akan memperoleh ratarata densitas yang tidak signifikan dan mempengaruhi kualitas gambaran menjadi tidak optimal.

Foto dari Langkah pertama dan kedua dapat dilihat dengan kasat mata bahwa pada foto kedua nilai densitasnya lebih rendah dibanding foto pertama. Hal ini dikarenakan saat posisi duduk tegak inspirasi yang diambil akan lebih mudah sehingga udara yang masuk kedalam paru-paru akan lebih banyak dan menghasilkan densitas yang lebih hitam dari pada saat pasien posisi supine. Pada penelitian "Perbandingan densitas dengan arah sinar Vertikal dan Horizontal di Radiologi RSUD Serang Banten (Ahmad Fahrurrozi Firdausy, 08006)" Dilakukan penelitian dengan menggunakan obyek Kepala, Shoulder Joint, $B N O$ dan Femur. Dari hasil penelitian diperoleh setiap obyek yang difoto menghasilkan densitas yang berbeda jika dibandingkan antara arah sinar Vertikal dan Horizontal pada obyek yang sama. Nilai densitas yang tidak terlalu berbeda terlihat pada foto kepala dan shoulder joint. Sedangkan nilai densitas yang sangat signifikan perbedaannya terjadi pada foto $B N O$ danfemur.

Dari hasil percobaan langkah pertama dan kedua diperoleh ukuran jantung pada posisi pasien supine $12 \mathrm{~cm}$ dan pada pasien duduk tegak 11,5. Perubahan ukuran jantung ini dipengaruhi oleh posisi pasien dimana pada saat pasien supine posisi jantung akan lebih melebar sehingga lebih besar dan pada saat pasien duduk posisi jantung akan lebih memanjang ke bawah karena grafitasi sehingga ukuran jantung menjadi lebih kecil.

Pada foto Thorax seharusnya digunakan jarak fokus ke film $150 \mathrm{~cm}$. Tujuannya agar gambaran jantung lebih terlihat normal. Tetapi diruang pemeriksaan radiologi untuk Proyeksi AP Supine dipakai 
Jarak fokus ke film $100 \mathrm{~cm}$, karena dari tube pesawat ke meja pemeriksaan tidak akan sampai pada jarak $150 \mathrm{~cm}$. Pada pengambilan gambar ketiga pada langkah percobaan keempat, karena jarak tube dapat diatur lebih jauh, maka FFD diatur menjadi $150 \mathrm{~cm}$ agar ukuran jantung mendekati ukuran sesungguhnya. Perubahan jarak (FFD) akan mengurangi intensitas radiasi yang sampai ke pasien, sehingga faktor eksposi yang digunakan harus di koreksi sesuai hukum Inverse Square Low. Penghitungan hasil ratarata dari hukum tersebut adalah $18 \mathrm{mAs}$ yang setelah difoto dengan $\mathrm{mAs}$ tersebut dan dibandingkan dengan hasil foto proyeksi AP Supine maka menghasilkan perbandingan yang cukup jauh dengan selisih rata-rata densitas 0.20. Ukuran jantung pada pengambilan gambar ketiga adalah $11 \mathrm{~cm}$ lebih kecil dari ukuran jantung pada pengambilan gambar kedua yaitu $11,5 \mathrm{~cm}$

Dalam teori konversi nilai mAs dikatakan "Kenaikan nilai mAs dua kali akan menambah opasitas sebanyak dua kali dan menaikan densitas sebesar 0.3 OD”. Sehingga jika sebuah radiograf terjadi kelebihan densitas sebanyak 0.3 OD, maka untuk mengkoreksinya harus dilakukan pengurangan nilai mAs separuh dari nilai mAs yang digunakan. Pada hasil percobaan langkah pertama dan keempat diperoleh selisih 0.2 OD pada pemakaian mAs awal 18 mAs sehingga untuk mengkoreksinya dilakukan pengurangan nilai mAs menjadi 12 , tetapi karena dipengaturan faktor eksposi pesawat tidak bisa 12 maka nilai mAs menjadi 12.5 .

Pada langkah ketujuh pasien di foto kembali sama seperti langkah keempat, yang berbeda hanya faktor eksposinya yaitu $\mathrm{kV} 48$, mAs 12.5 dan FFD 150. Setelah itu dihitung nilai densitasnya dan mendapatkan rata-rata densitas 0.94. Jika hasil rata-rata densitasnya dibedakan dengan hasil foto pada langkah pertama yaitu 0.99. Maka selisih nilainya menjadi 0.04. Jika dihitung dalam presentase nilai mAs baru 12 dan mAs lama 8 maka persentasenya adalah $50 \%$.

Penelitian ini juga dibuktikan dengan menggunakan pasien yang berbeda. Pada pasien berbeda ini dilakukan foto Thorax dengan proyeksi AP supine dan duduk tegak. Faktor eksposi yang digunakan pada proyeksi AP supine adalah $\mathrm{kV}$ 48, mAs 8 dan FFD 100. Dan Faktor eksposi yang digunakan pada proyeksi AP duduk tegak adalah $\mathrm{kV} 48$, mAs 12.5 dan FFD 150. Setelah dihitung nilai ratarata densitas pada foto supine yaitu 1.02 sedangkan foto duduk tegak yaitu 1.01. Dan selisih nilainya adalah 0.01. Diperoleh juga ukuran lebar jantung pada pasien supine 12,7 $\mathrm{cm}$ dan pada pasien duduk tegak dengan FFD $150 \mathrm{~cm}$ diperoleh ukuran jantung $11,3 \mathrm{~cm}$

\section{Simpulan}

Berdasarkan penelitian dari hasil perbandingan rata-rata densitas pada foto Thorax Proyeksi AP Supine dan AP Duduk Tegak yang dilakukan penulis, penulis dapat menyimpulkan :

1. Terdapat perbedaan rata-rata densitas yang signifikan antara hasil foto Proyeksi AP Supine dan AP Duduk Tegak. Nilai rata-rata densitas pada foto AP Supine lebih besar dibanding AP Duduk Tegak

2. Untuk menghasilkan rata-rata densitas yang hampir sama pada proyeksi AP supine dengan FFD $100 \mathrm{~cm}$ dan proyeksi AP duduk tegak dengan FFD 150 maka perlu ditambahkan nilai mAs sebesar $50 \%$ pada proyeksi AP duduk tegak dari nilai mAs yang dipergunakan pada proyeksi AP supine

\section{Daftar Pustaka}

Balinger, Philips W. 1995. Merils atlas of Radiographic position and Radiologic Procedure, 8 edition. Volume 1. United states of America: Mosby Company Toronto.

Ball, Jhon and Tony Price. 1989. Chesney's Radiographic Imaging, Fifth Edition. London.

Carlton, Richard R. Dkk. 1992. Principles of Radiodiagnostic Imaging an Art and a Science. Delmar Publishes, Inc. New York.

Evelyn C, Pearce. 2000. Anatomi dan fisiologi untuk paramedis, Jakarta: Gramedia 
Pustaka Utama.

Nadzri, Mohamed. 2014. Pocketbook Guide to Radiographic Image Evaluation, UiTM Press. Malaysia

Plaats, Van D. 1969. Former Chief Radiologist st. Annadal Hospital. Maastricht, CPC. Netherlands.

Rasad, Sjahriar. 2005. Radiologi Diagnostik,Edisi Kedua, Penerbit FKUI. Jakarta.

TBCTA, 2008. Handbook for District Hospital in Resource Constrained Settings on Quality Assurance of Chest Radiography for better TB control health system strengthening, KNCV. Netherlan 